\title{
Nurses' Perception toward their Rights and its' Relation to Job Satisfaction at Benha University Hospital ${ }^{1}$ Hamees Elsayed Hamed, ${ }^{2}$ Nermin Mohamed Eid, ${ }^{3}$ Aya Ghoneimy Hasanin
}

\author{
Nursing Administration, Faculty of Nursing, Benha University, Professor of Nursing \\ Administration, Faculty of Nursing, Menoufia University. Nursing Administration, Faculty of \\ Nursing, Benha University.
}

\begin{abstract}
Meeting nurses' rights are very important, because it affects the total outcome of hospital productivity, quality of care and nurses job satisfaction. The purpose of the study is to. assess nurses' perception toward their rights and its' relation to their job satisfaction at Benha University Hospital Adescriptive correlational design was utilized to meet the purpose of this study The study sample included 214 staff nurses working at Benha University Hospital Three instruments were used for data collection namely personal characteristics questionnaire, nurses' rights questionnaire and nurses' job satisfaction questionnaire. The results showed that about two thirds of staff nurses $(65.9 \%)$ perceived their rights, More than half of staff nurses (54.6\%) had low job satisfaction level and there was a highly statistically negative correlation between staff nurses' perception toward their rights and their job satisfaction. The study concluded that about two thirds of staff nurses (65.9\%) perceived their rights, More than half of staff nurses (54.6\%) had low job satisfaction level,. There was a highly statistically negative correlation between staff nurses' perception toward their rights and their job satisfaction. The study recommended that hospital administrator should encourage nurses' participation in decision making forums within the hospital, there should be clear job description with a defined set of duties, responsibilities and rights for staff nurses and there should be continuous education center within the hospital to enhance nurses' development.
\end{abstract}

Key words: Nurses' rights - Nurses' Perception - Job satisfaction.

\section{Introduction:}

Nursing as an integral part of the health care system, encompasses the promotion of health, the prevention of illness, and care of the physically ill, mentally ill, and disabled people of all ages, in all health care and other community settings. The mission of nursing in society is to help individuals, families and groups to determine and achieve their physical, mental and social potential, and to do so within the challenging context of the environment in which they live and work (Johnkenned et al., 2014).

Nurses' rights legitimate the power and responsibility of the profession. Nurses' rights can be divided into: human and civil rights, rights are based on health care legislation, professional rights, and earned rights. Analyzing nurses' rights will help to promote these rights, improve nurses' position both nationally and internationally, and provide possibilities for enhancing patient care because nurses' rights support them in various workplace situation, including unsafe staffing, mandatory overtime, health and safety issues as needle stick injuries and workplace violence ( Kangasniemi et al., 2010).

Nurses, as people and as professional have certain rights, many of which are sometimes not given the necessary recognition. This leads to demoralization, frustration and even anger on the part of nurses. While recognition of nurses' rights legitimate 


\section{Hamees Elsayed Hamed, Nermin Mohamed Eid, Aya Ghoneimy Hasanin \\ "Nurses' Perception ..."}

the power and responsibility of the profession. These rights are classified into five categories that include (Administrative, performance, Financial, Security, and professional) rights (Geyer et al.,2009).

Nurses have the right to share in unit decisions related to nursing issue. and informed nurses with the hospital labor law and a regulation is also considered one of the nurses' rights. Participation in decision making originates from the idea of participative management which supports staff to share with the goals and work of the organization, as a consequence create the chance for persons to have a sense of personal achievements Unfortunately, participation in decision making is often neglected in the nursing profession and is disregarded in the area of health (Ahmed \& Safadi, 2013).

Performance appraisal is the "process of observing and evaluating an employee's performance, recording the assessment, and providing feedback to the employee'. Nurses have the right to share in determining the evaluation criteria, have fair evaluation, have continual feedback of their level of performance and object to their evaluation (Magdalen et al., 2013).

Nurses' needs and wants are satisfied when they perceive that rewards from the hospital including compensation, promotion, recognition, development, and meaningful work, meet or exceed their expectation. Nurses have right to have appropriate income for their work as sufficient salary, paid overtime, and annual leave (Stievano et al., 2013).

Workplace safety is an important yet challenging matter for organizations especially in the healthcare sector. Nurses have the right to safe work environment to practice in a manner that assures the provision of safe care through adherence to professional standards and ethical practice and this is achieved through provision of better and modern equipment, safety of work place, security of health workers and quality working condition (Ayamolow et al., 2013).

Professional rights of nurses are grounded on international or national ethical codes or principles and labor laws. These rights consist of the right to perform the profession, getting respect from other health professionals and the society, enhancing the social status that the profession brings and the right to practice in a healthy, secure and ethical environment, they also have the right to advocate for patients' interests. As a part of their professional rights, using their expertise to provide care to patients and accrued rights of nurses obtained by education and work experience (Bahcecik et al., 2016).

Nurses' job satisfaction plays a key role in system productivity and patient safety. Analysis of 'job satisfaction' among nursing staff is crucial in understanding the existing gaps in achievement of higher levels of quality of care and patient safety. Moreover, knowledge on determinants of job satisfaction will aid management systems in the recruitment of more committed nurses and subsequent higher staff retention. Better patient care is a direct outcome of high job satisfaction rates among nursing staff, whereas their dissatisfaction leads to a shortage of staff with a knock-on impact on nurse-patient ratios, longer patient waiting lists, and burnout among healthcare personnel (Abdullah, 2015).

In health care organizations, it is very essential to determine factors associated with job satisfaction since this will ensure the provision of quality of care, as well as organizational efficiency, and effectiveness. Additionally, job satisfaction ensures 
the sustainability of health care professionals in the health care systems. So, proper understanding of factors of nurses' job satisfaction is essential for proactive managers to take necessary action (Masum et al., 2016)

As being happy is the right of human being so, nurses must be happy. Thus, "highly satisfied nurse has better physical and mental wellbeing" when nurses are not satisfied with the task assigned to them, they are not certain about factors such as their rights, working conditions are unsafe, coworkers are not cooperative, supervisor is not giving them respect and they are not considered in the decision making process; resulting them to feel separate from the organization (Ojulu, 2015).

\section{Significance of the study:}

Health care workers play an indispensable role in the implementation of health policy and the provision of health care services. However, their rights are frequently overlooked, and it is noted that nurses' rights have not been sufficiently addressed in the last decade, where their duties towards patients have been discussed in various ways and many health care workers complain of poor conditions of service, long hours and low wages. (Vawda., \&Variawa., 2012). In additional, Bahcecik concluded that $(76 \%)$ of nurse's rights were not protected and $(55 \%)$ of nurses believed that their rights were not protected at public hospitals. However, $56.8 \%$ of the nurses stated that their rights to job security were protected (Bahcecik et al., 2016).

Nurses are considered to be the vertebral column of any health care organization, nurses who are satisfied with their job are not only pleased but have also positive attitude, and high level productivity, creativity .This in turn will affect the quantitative outcomes of the health organization in appositive way .While dissatisfied nurses are disappointed and have negative attitude, poor performance and less productivity, increased absenteeism, burnout. Thus, they may quit their work place resulting in negative outcomes for the health care system. Therefore keeping them satisfied in their job is very important subject (El-salibi,2012). So this study was conducted to identify nurses perception toward their rights and its' relation to their job satisfaction at Benha University Hospital.

\section{Purpose of the study:}

The purpose of the present study was to assess nurses' perception toward their rights and its' relation to their job satisfaction at Benha University Hospital

\section{Research Questions}

1. What is the perception of nurses toward their rights at Benha University Hospital?

2. What is the level of nurses 'job satisfaction at Benha University Hospital?

3. Is this relation between nurses' perception toward their rights and their job satisfaction at Benha University Hospital?

\section{Methods:}

Design: A descriptive correlational research study was utilized to conduct this study.

Setting: This study was conducted in critical care units at Benha University Hospital.

Sampling: It included all staff nurses working at critical care units.

Instruments of data collection: three instruments were used for data collection in this study. 
Instrument one: $\quad$ Personal characteristics questionnaire: It included data about staff nurses as (age, sex, marital status, education, years of experience)

\section{Instrument two: Nurses' rights} questionnaire: It was used to assess nurses' perception toward their rights It was developed by $(\mathbf{A z o z}, 2013)$ and was modified by the researcher.based on reviewing the related literature (Bahcecik et al.,2016; Kangasniemi et al.,2014 ). It included (67) items divided under five categories which are administrative rights (13) items, performance appraisal rights (9) items, financial rights (8) items, security right (13) items and professional and professional development rights (24) items.

\section{Scoring system}

Subjects' responses were scored on three point likert scale as follow, 2 (Yes),

1 (Uncertain) and 0 (No). The score of each dimension summed up and converted to percent score. The staff nurses perceived their rights if the percent score were more than $75 \%$. (101-134). And not perceived their rights if the percent score was less than 75\% (0-100) (Abdullah,2012).

Instrument three: Nurses' job satisfaction questionnaire: It was used to assess nurses' job satisfaction. It was developed by (Esayed., 2014) and was modified by the researcher based on reviewing the related literature (Hamouda,2016; Ojulu,2015; ElShahat, 2014). It included (69) items divided under eight categories. They are hospital policy (7)items, relation at work (12) items, work environment and safety (17)items, work system (8) items, criteria for success (6) items, salary and incentives (4) items, achievement (12) items and psychological state (3) items.

\section{Scoring system:}

Subjects' responses were scored on three point likert scale as follow 2 (Satisfied), 1 (Neutral) and 0 (Un satisfied). The score of each dimension summed up and converted to percent score .The satisfaction of staff nurses with their job was considered high if the score more than $75 \%$. Moderate if the percent score was ranged from 50 to $75 \%$. While it considered low if the percent score less than $50 \%$ (AbdEImonem, 2016).

\section{Reliability of instruments.}

Reliability of nurses' rights questionnaire was measured by using Cronbach's Alpha and the value was (0.88) and reliability of Nurses' job satisfaction questionnaire was measured by using Cronbach's Alpha and the value was $(0.91)$

\section{Tools validity .}

Face and content of study tools were validated by jury group consisted of Five Experts from Nursing Administration and Public Health Nursing. Three Assistant Professors from Tanta University and Two Assistant Professors from Benha University. It took one month (Aprile) 2017, minor modification were done based on jury opinions.

\section{Pilot study:}

Pilot study was conducted in July 2017 to assess tool clarity and applicability. It has also served in estimating the time needed for filling the form . The study was tested on $10 \%$ of total subjects, it was done on 21 staff nurses. No modification was needed, so staff nurses were included in the main subject. The necessary clarification for some statements related to their translation to Arabic was done.

Filed work: 
An official permission was issued from Dean of the Faculty of Nursing to the Director of Benha University Hospital and from all participants in the study through official letters that sent to the heads of departments explaining the purpose of the study to obtain their approval to conduct the study. The researcher distributed instruments and instructions were provided regarding filling data collection instruments. This was done individually or during group meetings. The researcher distributed the questionnaire sheets to the participated staff nurses to fill it during work times which determined before with nurses. Data was collected 3 days/ week starting from from July / 2017 to September $/ 2017$.

\section{Ethical Considerations:}

Before conducting the study, explanation of the nature and the purpose of the study was done for staff nurses. They were told that participation in the study was voluntary. And informal consent was obtained from each participant in the study. Confidentiality of data was assured and protected by the allocation of a code number to the questionnaire sheets. Subjects were informed that the content of the tools would be used for the research purpose only. Participants' right to withdraw from the study at any time was ascertained.

\section{Statistical Design}

A computerized data entry was done to prepare data for statistical analysis. Statistical analysis was done fulfilling using Statistical package for social science (SPSS) Version twenty. Descriptive statistics was done in the form of mean and standard deviation for quantitative variables and frequency distribution for quantiitative variables. Qualitative categorical variables were compared using chi-square test. Pearson correlation coefficient was calculated to detect relation between variable, Fisher exact test was used for cells $<5$. Statistical significance was considered if P-value $\leq 0.05$ and highly statistical significant difference was considered if $\mathrm{P}$-value $\leq 0.001$.

\section{$\underline{\text { Results }}$}

Table (1): shows that more than half of staff nurses $(51.9 \%)$ ranged from 20-30 years old with mean score $30.09 \pm 6.89$. Regarding to gender, the majority of staff nurses $(93.0 \%)$ were female. Regarding to Educational level about half of staff nurses (49.1\%) had high average diploma in nursing. for years of experience, about one third of staff nurses $(32.7 \%)$ had less than 5 year of experience with mean score $11.07 \pm$ 8.19. Regarding to marital status the majority of staff nurses were married.

Figure (1): Shows that about two thirds of staff nurses $(65.9 \%)$ perceived their rights. While more than one third of staff nurses $(34.1 \%)$ were not perceived their rights..

Figure (2): Shows that (4.7\%) of staff nurses had high job satisfaction level, more than two fifths of staff nurses had moderate job satisfaction level, and while more than half of staff nurses (54.6\%) had low job satisfaction level

Table (2): Demonstrates that there was a highly statistically negative correlation between staff nurses' perception toward their rights and their job satisfaction. This means that when staff nurses perception toward their rights increase, their job satisfaction decrease.

Table (1): Distribution of the Studied Nurses according to Personal Characteristics ( $n=214)$ 


\begin{tabular}{|c|c|c|c|}
\hline Items & No. & $\%$ & \\
\hline Age (years) & & & \\
\hline $20<30$ & 111 & 51.9 & \\
\hline $30<40$ & 74 & 34.6 & \\
\hline $40<50$ & 27 & 12.6 & \\
\hline$\geq 50$ & 2 & 0.9 & \\
\hline Range & \multicolumn{3}{|c|}{$21-52$} \\
\hline Mean \pm SD & \multicolumn{3}{|c|}{$30.09 \pm 6.89$} \\
\hline Gender & & & \\
\hline Male & 15 & 7.0 & \\
\hline Female & 199 & 93.0 & \\
\hline \multicolumn{4}{|l|}{ Educational level } \\
\hline School diploma in nursing & 86 & 40.2 & \\
\hline Associated degree in nursing & 105 & 49.1 & \\
\hline Bachelor degree in nursing & 23 & 10.7 & \\
\hline \multicolumn{4}{|l|}{ Years of experience } \\
\hline $1<5$ & 70 & 32.7 & \\
\hline $5<10$ & 35 & 16.4 & \\
\hline $10<15$ & 66 & 30.8 & \\
\hline$\geq 15$ & 43 & 20.1 & \\
\hline Range & $1-$ & & 32 \\
\hline Mean \pm SD & \multicolumn{3}{|c|}{$11.07 \pm 8.19$} \\
\hline Married & 191 & $89.3 \%$ & \\
\hline Single & 23 & $10.7 \%$ & \\
\hline
\end{tabular}

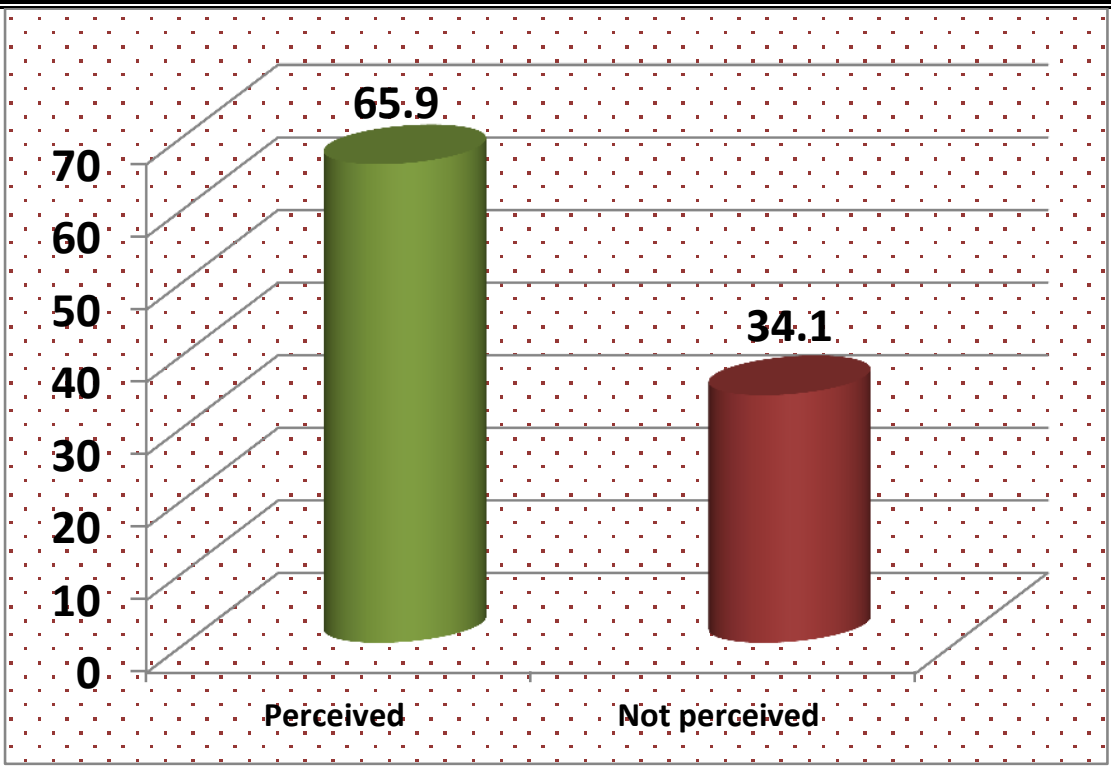

Figure (1): Staff Nurses Perception Regarding their Rights (n=214). 


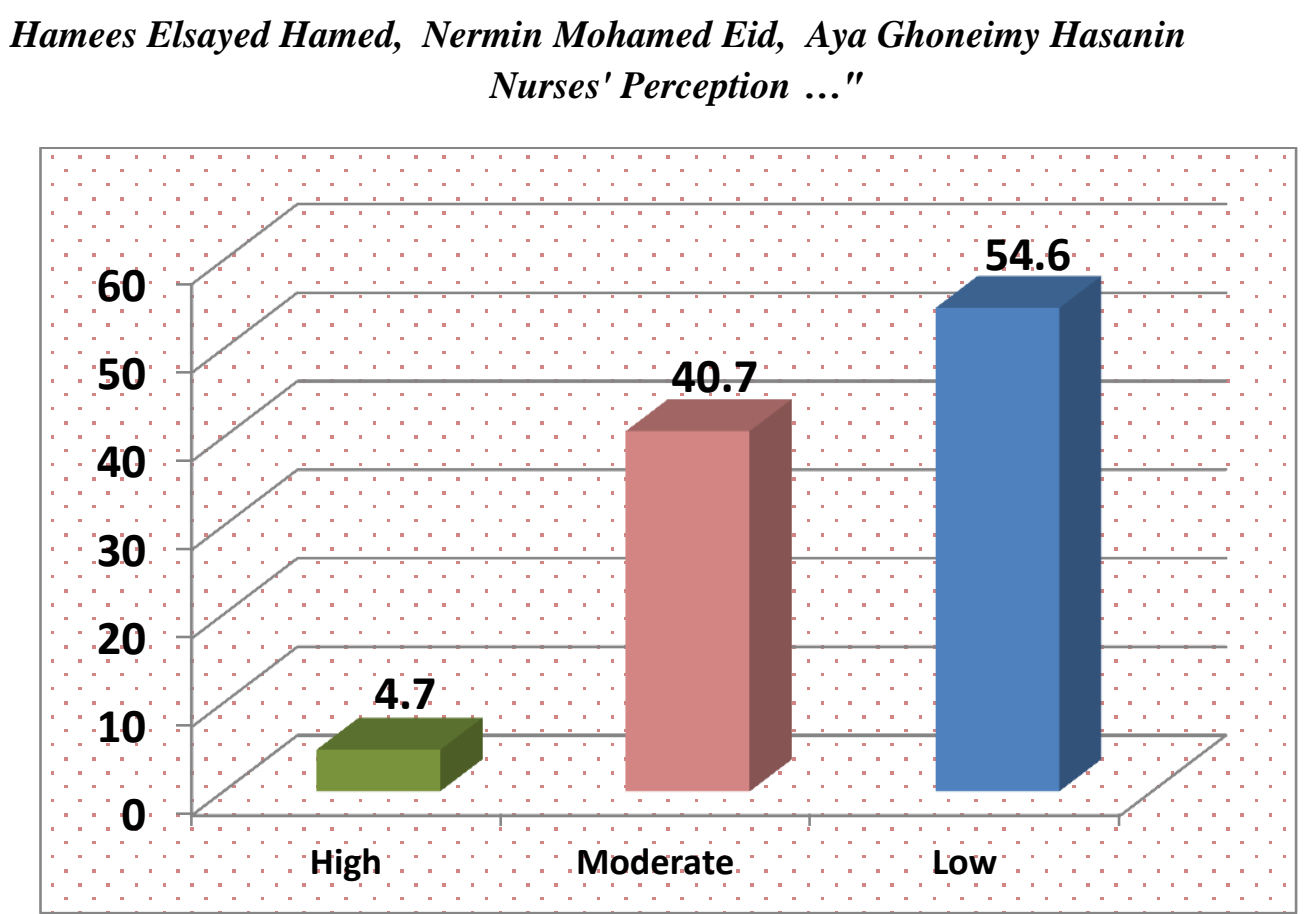

Figure (2): Staff Nurses Job Satisfaction Level $(n=214)$

Table (2) Correlation between Total Perception Score and Total Job Satisfaction Scores of Staff Nurse $(n=214)$

\begin{tabular}{|c|c|c|}
\hline \multirow{2}{*}{ Variables } & \multicolumn{2}{|c|}{ Total perception score } \\
\cline { 2 - 3 } & $\mathbf{r}$ & $\mathbf{p}$ \\
\hline Total satisfaction score & -0.637 & $0.000^{* *}$ \\
\hline
\end{tabular}

\section{Discussion}

The present study aimed to assess nurses' perception toward their rights and its' relation to their job satisfaction at Benha University Hospital. Three questions were addressed in the study

(I) First question: What is the perception of nurses toward their rights at Benha University Hospital?

The present study results revealed that about two thirds of staff nurses $(65.9 \%)$ perceived their rights. From the investigators' point of view this finding might be related to nurses' experiences in nursing field, in addition their exposure to problems with patients and nursing administration, assigns of nonnursing activities for them, their relation with other nurses in other hospitals moreover, knowing of these rights through media. This result was consistent with Azoz,2013) who reported that the majority of nurses are aware of their rights. On the other hand this finding was contradicted with Kangasniemi et al, (2014) who reported that nurses in Turkey have never cared for and was not aware of their own rights. Moreover (Bahcecik et al,2016) reported that the majority of their participants were not aware of their rights.

(II) Second question: What is the level of nurses 'job satisfaction at Benha University Hospital?

The present study revealed that more than half of staff nurses $(54.6 \%)$ had low job satisfaction level. This result could be related to nurses' work in an environment that doesn't meet their needs for their participation in hospital decision, nursing decision, provision of necessary equipment, infection control 
supplies such as gloves, medical supplies such as cotton, gauze in addition the daily workloads and work conflicts. Moreover, they felt that their wages were less than nurses in other hospitals.

This finding was congruent with Haile et al(2017) who reported that the most of their respondents had low level of job satisfaction, also this result was consistent with Park et al,(2012) who reported that nurses were least satisfied with their job in comparison with other professionals like allied health professionals, school teachers, and social workers and this finding was congruent with Aljuhani and Kishk (2012) the majority of nurses working in Al- Madina Al- Munawwara, Saudi were dissatisfied with their job. In addition, the previous findings agreed with Sabanciogullari and Dogan,(2015) who identified that generally nurses' satisfaction level is low in Turkey.

(III) Third question: Is this relation between nurses' perception toward their rights and their job satisfaction at Benha University Hospital?

The present study revealed that there was a highly statistically negative correlation between staff nurses' perception toward their rights and their job satisfaction. On my respective this might be due to that nurses at Benha University Hospital perceived their rights but these rights not implemented and not protected from hospital administration and they work in an environment that does not meet their needs so they not satisfied with their job.

This finding was congruent with Azoz (2013) who reported that there is significant difference in almost all items perceived as important nurses' right in each dimension and the extent to which these rights are fulfilled by the hospital and they not satisfied with their work in an environment that not meet their expectation. Also, this finding was congruent with (Bahcecik et al,2016) who reported that nurses' rights are ignored and overlooked by the hospital and the majority of nurses reported that their rights were not protected at public hospital and they not satisfied with their work at public hospital and they intended to leave it and go to the private hospital.

\section{Conclusion}

It was concluded that about two thirds of staff nurses perceived their rights, more than half of staff nurses had low job satisfaction level and there was a highly statistically negative correlation between staff nurses' perception toward their rights and their job satisfaction.

\section{Recommendations}

1) Hospital administrator should encourage nurses' participation in decision making forums within the hospital

2) Nursing personnel have to be represented in the hospital committees such as quality control, and infection control committees.

3) The nursing director should be a member in the hospital governing board.

4) There should be clear job description with a defined set of duties, responsibilities and rights for staff nurses.

5) Head nurse should notify nurses with the required performance standard.

6) There should be sufficiency of medical supplies and equipment.

7) There should be strategies to improve nurses' salary and incentives.

8) Periodic meeting of staff nurses with nursing director to discuss and solve their work problems.

9) There should be continuous education center within the hospital to enhance nurses' development.

10) Conduct studies at Ministry of 
Health Hospitals to assess nurses' perception toward their rights and investigate the difference between university and health hospitals.

11) Conduct studies about how to access and comply with nurses' rights at hospitals.

12) Conduct studies to investigate factors that enhance level of job satisfaction among nursing personnel.

\section{References:}

Abdullah, A.(2015): Nursing Satisfaction in a Magnet Hospital, Unpublished PHD Theses, University of Rhode Island.

Ahmed , M., Safadi, E.(2013): Decisional Involvement among Nurses: Governmental Versus Private Hospitals, Health Science Journal,7, (1) :pp18-27.

Al Juhani, A. M. and Kishk, N. A. (2012). Job Satisfaction Among Primary Health Care Physicians and Nurses in AlMadinah AlMunawwara. The Journal of the Egyptian Public Health Association (JEPHAss.), 81 (3and 4), 165-180.

Ayamolowo, S., Irinoye, O., and Oladoyin, M. (2013): Job satisfaction and Work Enviroment Of Primary Health Care Nurse In Ekitistate, Nigeria: An Exploratory study, International Journal of Caring Sciences,6,(3):pp531-542.

Azoz, M.,(2013):Identifying Nurses' Perception Of their Rights And Its' Influence on Decision Making at Benisuf University, Unpublished Master Theses, Faculty of Nursing, Cairo University.

Bahcecik, N., Ozturk, H., \&Tiryaki, H. (2016): Protection Of Nurses Rights In Turkey A study on Nurses Opinions, Journal of
Pakistan Medical

Association,66,(9):pp111-1115.

El-salibi, B.,(2012):Job Satisfaction Among Registered Nurses Working in UAE Ministry Of Health Hospitals: Demographic Correlates, Unpuplished Master, Faculty of Education, The British University in Dubai

Geyer, N., Mogotlane, S., and Yong, A. (2009): Jutas' Mnual of Nursing , $2^{\text {nd }}$ edition, pp245-246, Juta and company New York.

Haile, D., Gualu, T., Zeleke, H., and Dessalegn, B. (2017): Job Satisfaction and Associated Factors among Nurses in East Gojjam Zone: Public Hospitals Northwest Ethiopia, 2016 Journal of Nursing and Care,2016,(1):PP3-6

Johnkennedy, N., Constance,N., and Hope, O. (2014): Areview on Nursing Diagnostics, Journal of Advanced Nursing Practice, 1, (1): pp17-20

Kangasniem, M., Vitalahde, K., and Porkka, S. (2010): Theoretical examination of the Rights of Nurses, Nurse Ethics 2010, 1, (2):pp35-62

Kangasniemi, M., Maijapietila, A., and Utriainen, $K$. (2014): Gerontological Nurses' Perception of their Rights in Finland, Scandinavian Journal of Sciences, 28, (1): pp347-384.

Magdalene, H., Marthie, C., and Janetta, H. (2013): Factors affecting the Performance of professional nurses in Namibia, Journal of the Democratic Nursing Organization of south Africa,36,(1):pp1.

Masum,A., Azad, M., Hoque, K., Beh, L., Wanke, P., and Arslan, 
O. (2016): Job satisfaction and intention to quit: an empirical analysis of nurses in Turkey, Peer Journal,4,(1):pp1-23

Ojulu, P. (2015): The Relation between Leadership Style and Job Satisfaction Staff in Teachers' Education and Health Science College of Gam Bella People's National State, Unpublished Master Theses, College of Education and Behavioral Studies, Addis Ababa University.

Park M, Lee J, Cho S. (2012): Newly Graduated Nursese ${ }^{\text {ee }}$ Job Satisfaction: Comparison with Allied Hospital Professionals, Social Workers and Elementary School Teachers. Asian, Nursing Research. Sep 6,(3):PP85-90.
Sabanciogullaries, S., Dogan, S. (2015): Effect of the Professional Identity Development Programme on the Professional Identity, Job satisfaction and Burnout Levels of Nurses: A pilot study, International Journal of Nursing Practices, 21,(6):pp847-857

Stievano,A., Kangasniemi, M., and Pietilaa,M.(2013):Nurses

Perception of their Professional Rights, Nursing Ethics 2013,20, (4):pp69-45

Vawda, Y., and Variawa, F., (2012): Challenges Confronting Health Care Workers in Governmentsarv Rollout :Rights and Responsibities ,P.E.R /P.E.L Journal ,15,(2):PP487-569 